\section{AB0451 PROSPECTIVE STUDY OF REASONS FOR DISCONTINUATION OF TOFACITINIB IN SELF-FUNDED PATIENTS WITH RHEUMATOID ARTHRITIS FROM A SINGLE CENTRE}

Ramakrishna Rao Uppuluri, Maryam Younis, Archana Rani, Shashikala Arava, Shivanand Jonnada, Kumar Datta, Challa Satyavati. Sri Deepti Rheumatology Centre, Rheumatology, Hyderabad, India

Background: Tofacitinib is an oral Janus kinase inhibitor for the treatment of Rheumatoid Arthritis (RA). There can be potential differences in the adherence and compliance to therapies in real world compared to clinical trials especially in a non-reimbursable setup. Hence, it is very important to see the patient persistence to Tofacitinib therapy in a real world practice.

Objectives: To evaluate the reasons for discontinuation of Tofacitinib in RA patients in real world set-up.

Methods: Data of RA patients treated with Tofacitinib $5 \mathrm{mg}$ BID from a rheumatology center in South India was collected from September 2016 to January 2019 using standardized formats at baseline, 1, 3, 6 and 12 months. Efficacy was evaluated by DAS28-ESR and safety by listing of Adverse Events (AE). Reasons for discontinuation were objectively recorded. Concomitant RA treatment type/dose adjustments were as per the clinician's discretion. Analysis was based on observed values without imputation for missing data. For calculating persistence at a time point, the patients still taking the drug with treatment duration lower than that particular time point were excluded from the calculation.

Results: Fifty seven RA patients were treated with Tofacitinib. Average age and disease duration were 50 (20-77) years, 9 (1-22) years respectively. Most patients were females $(88 \%)$; seropositive $(89 \%)$ and all had erosive disease. Tofacitinib was used as a second line drug after inadequate response with conventional Disease Modifying Anti Rheumatic Drugs. Average Tofacitinib follow up was 6 (1-16) months. Thirty nine patients who discontinued Tofacitinib were analyzed. Eighteen patients were at various stages of therapy including 8 patients completing 12 months. Persistence with Tofacitinib at 3,6 and 12 months was 85, 50 and 17 percent respectively. Details of the reasons for discontinuation are given in Table and Figure.

Conclusion: Tofacitinib was effective and well tolerated in Indian patients. However, majority of patients $(80 \%)$ discontinued at various time points after feeling better. Only $13 \%$ discontinued due to AEs and $7 \%$ due to inadequate response. This data brings into light the difficulties faced by health providers for implementing 'treat to target' approach in real world practice.

\section{Reasons for Discontinuation}

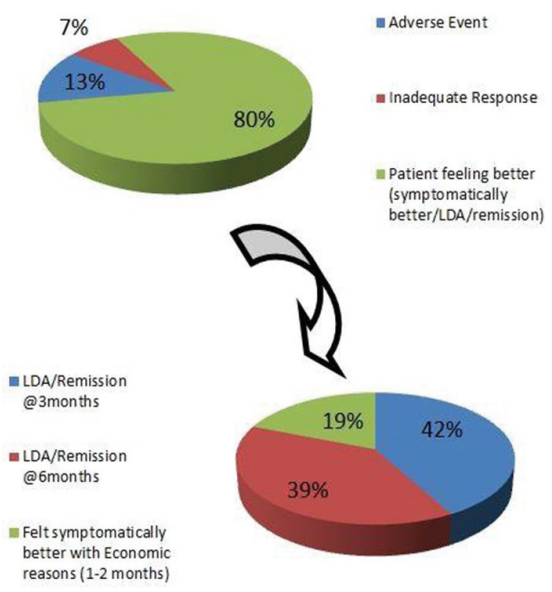

Figure 1

\section{REFERENCES}

[1] Marchesoni et al, Ann NY Acad Sci 2009, 1173: 837-846

\begin{tabular}{|c|c|c|c|c|}
\hline \multirow[t]{2}{*}{ Reasons for Discontinuation } & \multicolumn{3}{|c|}{ Duration of treatment (Months) } & \multirow{2}{*}{$\begin{array}{c}\text { Number of } \\
\text { patients }\end{array}$} \\
\hline & $\begin{array}{c}1-3 \\
\text { months }\end{array}$ & $\begin{array}{c}3-6 \\
\text { months }\end{array}$ & $\begin{array}{c}6-12 \\
\text { months }\end{array}$ & \\
\hline
\end{tabular}

$15(13 \%)$

Inadequate response (IR) Symptomatically better/LDA Remission

- Patients' perception as

3 month course only

- Patients' perception as

6 month course only

- Economic reasons

Number of patients

Disclosure of Interests: Ramakrishna Rao Uppuluri Grant/research support from: Pfizer Inc, Maryam Younis: None declared, Archana Rani: None declared, Shashikala Arava: None declared, Shivanand Jonnada: None declared, Kumar Datta: None declared, Challa Satyavati: None declared DOI: 10.1136/annrheumdis-2019-eular.5684

\section{AB0452 SYSTEMATIC REVIEW OF GUIDELINES ON THE USE OF METHOTREXATE IN RHEUMATOID ARTHRITIS}

Valeria Valerio Guillen ${ }^{1}$, Carol Hitchon ${ }^{2}$, Hal Loewen ${ }^{2}$, Girish Mody ${ }^{3}$,

Ines Colmegna ${ }^{1}{ }^{1}$ The Research Institute of the MUHC, Montreal, Canada;

${ }^{2}$ University of Manitoba, Winnipeg, Canada: ${ }^{3}$ University of KwaZulu-Natal, Durban, Canada

Background: Most guidelines on the use of methotrexate (MTX) in rheu matoid arthritis (RA) are issued by developed countries. MTX use in African 'least developed countries' (LDCs) requires considering costs of medical care, limited manpower and patients' beliefs. It is unknown whether current available MTX guidelines are relevant to LDCs.

Objectives: To review existing guidelines/recommendations on the use of MTX for the treatment of RA prior to developing recommendations for LDCs.

Methods: Electronic databases and guideline registries were searched for guidelines on MTX use in RA. Reviewers eliminated duplicates and selected the most updated guidelines. Similarities and discrepancies among recommendations are reported.

Results: From 2111 citations, 23 full texts were screened and 13 included in the qualitative synthesis. Guidelines targeted rheumatologists (3/13) and other physicians involved in RA care (7/13). Half (6/13) of the guidelines comment on patient education. MTX is suggested as the first DMARD choice by $5 / 13$ guidelines. Screening for risk factors associated with a higher risk of MTX toxicity (e.g. alcohol) is suggested in 4/13 guidelines. Eight guidelines discuss pre-MTX tests: all recommend baseline CBC, liver (mainly albumin and liver function tests), renal function tests (mainly serum creatinine) and $\mathrm{HBV} / \mathrm{HCV}$ serologies. Seven recom mend a baseline chest $X$-ray. Only $4 / 8$ and $2 / 8$ guidelines recommend HIV and TB screening respectively. Pneumococcus and influenza immunization are suggested by $3 / 13$ guidelines that comment on vaccines, whereas $\mathrm{HBV}$ and $\mathrm{HZV}$ vaccines by $2 / 13$. Pregnancy and lactation are stated as MTX contraindications by $5 / 13$ guidelines; four recommend MTX discontinuation 3 months prior to conception in females. Only 2/13 guidelines comment on the need of contraception in patients of reproductive age on MTX. MTX starting dose is discussed by $7 / 13$ guidelines: $>10 \mathrm{mg} / \mathrm{wk}$ (5/7); $12.5-15 \mathrm{mg} /$ week (1/7); and 6-8mg/week (1/7, guideline from Japan). The maximal dose of MTX recommended by $8 / 9$ guidelines is $20-30 \mathrm{mg} /$ week. Dose escalation $(2-5 \mathrm{mg}$ ) every $2-6$ weeks is discussed by $4 / 9$ guidelines. There is no uniformity on the initial administration route of MTX (3/6 oral, $3 / 6$ either oral or parenteral). The use of higher MTX doses, increasing adherence, and inadequate clinical responses or intolerance are suggested indications for switching from oral to parenteral route $(8 / 13)$. Folic acid supplementation is recommended by $8 / 13$ guidelines; however specific dose and time intervals are not defined. CBC, liver and kidney monitoring are recommended for MTX treated patients by $8 / 13$ guidelines. Specific laboratory investigations and monitoring intervals vary between guidelines. Eight guidelines agree that MTX could be continued throughout the perioperative period of elective orthopedic surgery. Three guidelines recommend MTX discontinuation in case of severe infection. MTX dose reduction is discussed by $3 / 13$ guidelines, which recommend considering reduction with sustained remission ( $\geq 6$ months).

Conclusion: Existing guidelines do not uniformly address all aspects related to the MTX use in RA, and do not include a cost-effectiveness analysis. Adaptation of these guidelines for their implementation in LDCs is needed.

Disclosure of Interests: Valeria Valerio Guillen: None declared, CArol Hitchon Grant/research support from: Pfizer, UCB (unrelated studies), Hal Loewen: None declared, Girish Mody: None declared, Ines Colmegna: None declared

DOI: 10.1136/annrheumdis-2019-eular.6404 